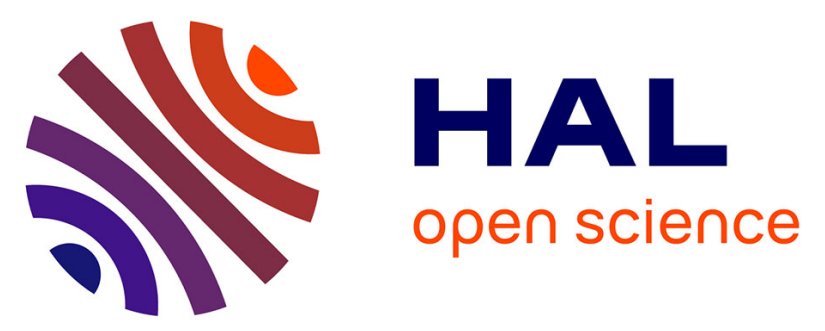

\title{
Modeling Potential Equilibrium States of Vegetation and Terrestrial Water Cycle of Mesoamerica under Climate Change Scenarios
}

Pablo Imbach, Luis Molina, Bruno Locatelli, Olivier Roupsard, Gil Mahe, Ronald Neilson, Lenin Corrales, Marko Scholze, Philippe Ciais

\section{To cite this version:}

Pablo Imbach, Luis Molina, Bruno Locatelli, Olivier Roupsard, Gil Mahe, et al.. Modeling Potential Equilibrium States of Vegetation and Terrestrial Water Cycle of Mesoamerica under Climate Change Scenarios. Journal of Hydrometeorology, 2012, 13, pp.665-680. 10.1175/JHM-D-11-023.1 . cirad00701344

\section{HAL Id: cirad-00701344 http://hal.cirad.fr/cirad-00701344}

Submitted on 25 Aug 2012

HAL is a multi-disciplinary open access archive for the deposit and dissemination of scientific research documents, whether they are published or not. The documents may come from teaching and research institutions in France or abroad, or from public or private research centers.
L'archive ouverte pluridisciplinaire HAL, est destinée au dépôt et à la diffusion de documents scientifiques de niveau recherche, publiés ou non, émanant des établissements d'enseignement et de recherche français ou étrangers, des laboratoires publics ou privés. 


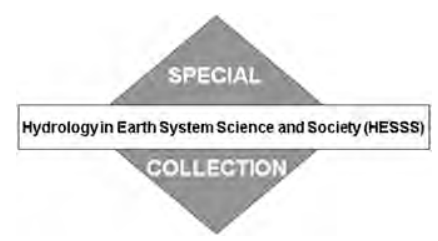

\title{
Modeling Potential Equilibrium States of Vegetation and Terrestrial Water Cycle of Mesoamerica under Climate Change Scenarios*
}

\author{
PAblo Imbach, ${ }^{+}$Luis Molina, ${ }^{+}$Bruno LocAtelli, ${ }^{\#}$ Olivier Roupsard, ${ }^{+, @}$ Gil Mahé, ${ }^{\&}$

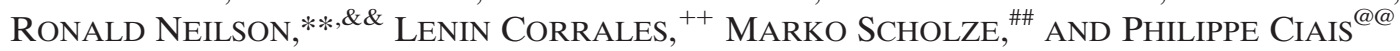 \\ + Climate Change Program, CATIE, Cartago, Costa Rica \\ \# CIRAD UPR Forest Ecosystem Services, Montpellier, France, and CIFOR ENV Program, Bogor, Indonesia \\ @ CIRAD-Persyst, UPR80, Fonctionnement et Pilotage des Ecosystèmes de Plantations, Montpellier, France \\ ${ }^{\&}$ IRD/HSM, University Mohamed V, Rabat-Agdal, Morocco \\ ** Pacific Northwest Research Station, USDA Forest Service, Corvallis, Oregon \\ ${ }^{++}$Apdo, San José, Costa Rica \\ \#\# School of Earth Sciences, University of Bristol, Bristol, United Kingdom \\ @ IPSL-LSCE, CEA CNRS UVSQ, Centre d'Etudes Orme des Merisiers, Gif-sur-Yvette, France
}

(Manuscript received 18 February 2011, in final form 7 November 2011)

\begin{abstract}
The likelihood and magnitude of the impacts of climate change on potential vegetation and the water cycle in Mesoamerica is evaluated. Mesoamerica is a global biodiversity hotspot with highly diverse topographic and climatic conditions and is among the tropical regions with the highest expected changes in precipitation and temperature under future climate scenarios. The biogeographic soil-vegetation-atmosphere model Mapped Atmosphere Plant Soil System (MAPSS) was used for simulating the integrated changes in leaf area index (LAI), vegetation types (grass, shrubs, and trees), evapotranspiration, and runoff at the end of the twenty-first century. Uncertainty was estimated as the likelihood of changes in vegetation and water cycle under three ensembles of model runs, one for each of the groups of greenhouse gas emission scenarios (low, intermediate, and high emissions), for a total of 136 runs generated with 23 general circulation models (GCMs). LAI is likely to decrease over $77 \%-89 \%$ of the region, depending on climate scenario groups, showing that potential vegetation will likely shift from humid to dry types. Accounting for potential effects of $\mathrm{CO}_{2}$ on water use efficiency significantly decreased impacts on LAI. Runoff will decrease across the region even in areas where precipitation increases (even under increased water use efficiency), as temperature change will increase evapotranspiration. Higher emission scenarios show lower uncertainty (higher likelihood) in modeled impacts. Although the projection spread is high for future precipitation, the impacts of climate change on vegetation and water cycle are predicted with relatively low uncertainty.
\end{abstract}

\section{Introduction}

There is a need to understand the potential impacts of climate change on ecological systems before defining adaptation measures for ecosystems and the people who depend on their services (MEA 2005). The Mesoamerican

\footnotetext{
* Supplemental information related to this paper is available at the Journals Online website: http://dx.doi.org/10.1175/JHM-D-11-023.s1.

\&\& Current affiliation: Department of Botany and Plant Pathology, Oregon State University, Corvallis, Oregon.
}

Corresponding author address: Pablo Imbach, CATIE 7170, Turrialba, Cartago 30501, Costa Rica.

E-mail:pimbach@catie.ac.cr region, where approximately 60 million people depend highly on natural resources, is a global biodiversity hotspot (DeClerck et al. 2010; Myers et al. 2000), with an estimated number of endemic vascular plant species of up to 5000 (Conservation International 2011; Greenheck 2002). It is a repository of the evolutionary history of biodiversity (Sechrest et al. 2002) and a bridge between North and South America for mammals (MacFadden 2006), birds (Weir et al. 2009), and plants (Gentry 1982). Countries in the region have developed national and regional policies for integrating biodiversity conservation and development [e.g., the Central American System of Protected Areas (http:// www.sica.int/) and the Puebla-Panama plan (http://www. proyectomesoamerica.org/)] that should account for future climate threats to help reduce the vulnerability of the region. 
Central America could be the tropical region [as commonly bounded by the Intergovernmental Panel on Climate Change (IPCC)] most exposed to climate change (Giorgi 2006). Between 1961 and 2003, the region experienced increased trends in temperature and in the fraction of annual precipitation falling during extreme events (Aguilar et al. 2005). Observed trends in annual rainfall differ in signal (positive or negative) and statistical significance depending on the data source used. Aguilar et al. (2005) found a nonsignificant trend based on weather station data while Malhi and Wright (2004) found significant increases in some areas based on spatial interpolation of weather station data over forest-covered areas. Furthermore, Neelin et al. (2006) found an observed decrease in precipitation trends based on remote sensing sources (except for southern Panama, which shows the opposite trend), but highlights the difficulty of discerning the natural multidecadal or interannual variability on these observed trends in tropical areas. Precipitation is projected to decrease in the future (Neelin et al. 2006) but uncertainties remain since the year at which the trend for each model is discernible from natural variability and at which several models agree on the trend is highly variable. However, the potential for extreme droughts in the region is becoming increasingly clear (Dai 2010). The impacts of these changes in climate on vegetation and hydrology will affect the availability of natural resources (i.e., water, biodiversity, and biomass) with implications for development. Although not related to human-induced climate change as in this study, an example from the region's history is the collapse of the Mayan civilization in northern Mesoamerica, which has been explained by multidecadal droughts and their impact on natural resources and livelihoods (Curtis et al. 1996; Haug et al. 2003).

The impacts of climate change on ecosystems depend on complex, nonlinear interactions among soils, vegetation, climate, and humans. These interactions can be simulated by process-based models that functionally integrate atmospheric, vegetation, and hydrologic responses that cannot be accomplished by correlative climate-vegetation models (Yates et al. 2000) and have been applied to modeling the impacts of climate change on vegetation and hydrology for all IPCC reports since 1995 (e.g., Cramer et al. 2001; Neilson and Marks 1994).

Projected impacts vary by model structure, model parameters, and input data, including future changes in climate (IPCC 2005). One approach to assessing uncertainties in projected impacts for the purpose of informed decision making is by using an ensemble of ecosystem models, general circulation models (GCMs), and emission scenarios. Calibrating and validating ecosystem models with past observations allows the uncertainties arising from the ecosystem model to be analyzed and reduced; however, uncertainties from climate scenarios cannot be diminished since the future will never be precisely predictable (in part because of the randomness of the climate system and interventions by human choice).

We aimed to assess the impacts of climate change on vegetation and the water cycle in Mesoamerica using the process-based Mapped Atmosphere Plant Soil System (MAPSS) biogeography model (Neilson 1995) with 136 climate realizations downscaled from the outputs of 23 global GCMs, from the IPCC Fourth Assessment Report, under low (B1), intermediate (A1B), and high (A2) emission scenarios for the 2070-99 period (Solomon et al. 2007). Specifically, we quantify the magnitude and uncertainties of climate change impacts on vegetation types, leaf area index (LAI), runoff, and evapotranspiration. Because of the complex topography and spatial climate variability in the region, we assessed the impacts at $1-\mathrm{km}$ resolution.

To our knowledge, it is the first application of a global vegetation model coupling water and vegetation interactions with climate scenarios for Mesoamerica. This study joins a small subset of studies aimed at modeling the nonlinear interactions between climate and terrestrial ecosystems at high spatial resolution under a large number of climate scenarios (Scholze et al. 2006).

\section{Materials and methods}

\section{a. Study area: Climate and vegetation}

The study area spans a $1000000 \mathrm{~km}^{2}$ area of land between $6.5^{\circ}-22^{\circ} \mathrm{N}$ and $76.5^{\circ}-99^{\circ} \mathrm{W}$ (excluding the Caribbean Islands). It extends from Panama in the south to southern Mexico in the north across six other Central American countries (Costa Rica, Nicaragua, Honduras, El Salvador, Guatemala, and Belize). The region is biophysically diverse with topography marked by the Central American cordillera that reaches over 4000 MSL and runs close to the Pacific coast (Fig. 1), leaving larger and longer basins on the Atlantic watershed. Climate is tropical and rainfall follows a bimodal seasonal cycle with high interannual variability (Magaña et al. 1999). In the Pacific watersheds and Yucatán, seasonal rainfall occurs from May to October, whereas rainfall occurs year-round in the Atlantic watersheds with a weaker bimodal seasonal cycle. Pristine areas are covered with savanna and dry forests in the Pacific watershed and Yucatán and evergreen forests in the Atlantic watershed. The region has a $42 \%$ cover of crops and pastures, $57 \%$ of natural vegetation, and $2 \%$ of urban areas (DeClerck et al. 2010) (Fig. 1). 


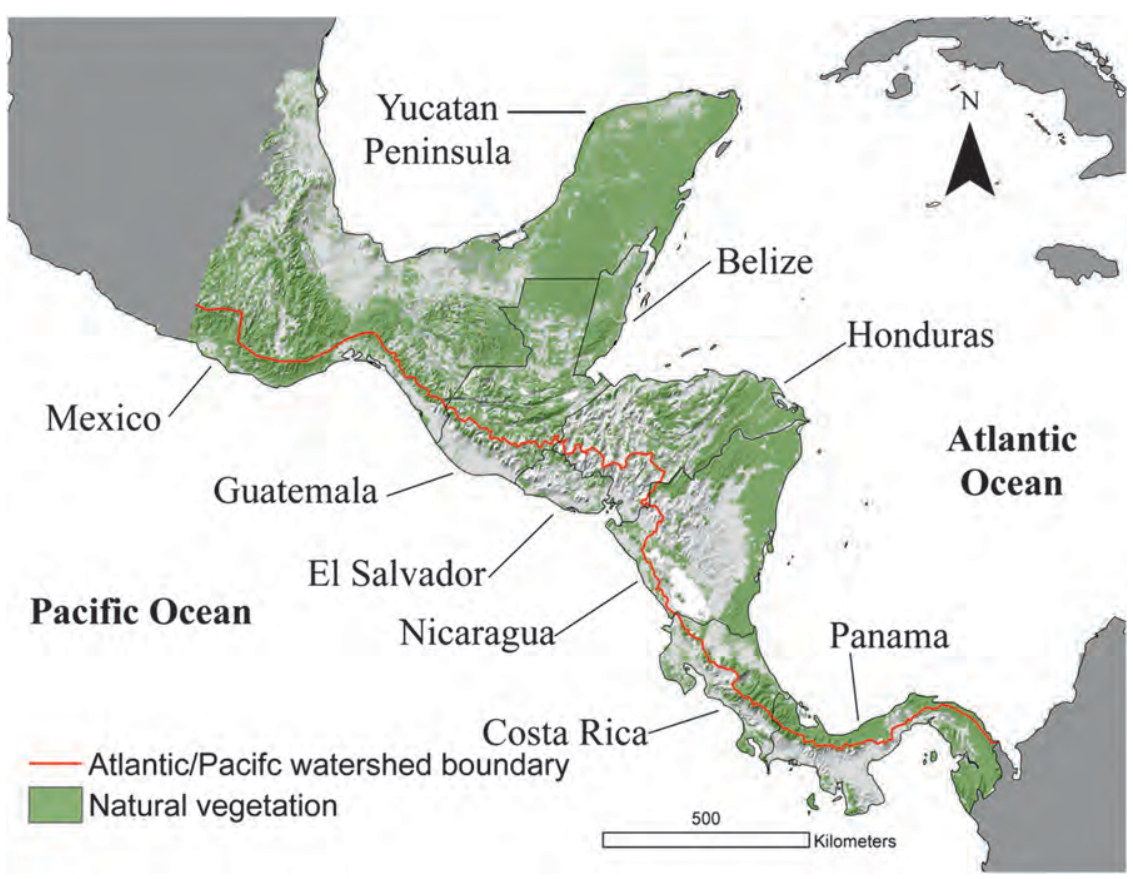

FIG. 1. Region of study: relief, areas with natural vegetation cover (for the year 2000; Vreugdenhil et al. 2002), watershed boundaries, and country limits (nonnatural areas comprise urban, agriculture, and livestock uses). This and subsequent maps are based on the Mollweide projection.

\section{b. Modeling approach}

MAPSS is an equilibrium biogeography model that simulates the long-term average water balance and potential vegetation, given an average climate, based on water and energy constraints (Neilson 1995). The model, described in detail by Neilson (1995), has been applied in earlier studies for modeling runoff and vegetation patterns of the United States (Bachelet et al. 1998; Bishop et al. 1998) and assessing the impacts of climate change globally (Neilson 1993b; Neilson and Marks 1994) and in North America (Bachelet et al. 2001; Neilson 1993b; Neilson and Drapek 1998; Scott et al. 2002). MAPSS simulates equilibrium runoff, evapotranspiration, LAI, and potential vegetation types (trees, shrubs, and grasses) as a function of climate (monthly means of temperature, precipitation, wind speed, and vapor pressure) and soils (column depth and texture). Vegetation types refer here to trees, shrubs, and grasses (equivalent to the "life forms" used in Neilson 1995). MAPSS is a general vegetation model (GVM), which is a relatively new class of models based largely on the fundamental principle that vegetation will continue to amass leaf area at a given location until it utilizes nearly all of the available soil moisture (Horton 1933).

The model assumptions are that potential equilibrium vegetation can be modeled based on climate and soil data and that the resulting water partitioning allows for runoff and evapotranspiration estimates at a regional scale (Imbach et al. 2010). The assumption that LAI and vegetation forms adjust according to soil moisture allows the model to search for an equilibrium of LAI, evapotranspiration, and soil moisture depending on temperature and precipitation (other effects on LAI equilibrium are not accounted for-i.e., nutrients' limitation). The equilibrium is found by increasing or decreasing LAI so most of the available water is used by the vegetation. It follows that if water is available, vegetation grows (LAI is increased) and runoff is reduced. When soil water is depleted, the LAI is reduced, which may not increase runoff but will buffer the reduction in runoff by reducing transpiration. Equilibrium LAI aggregates the LAI of woody (trees or shrubs) and grass vegetation types that are allowed to compete for light under an open canopy; when the canopy is closed by woody vegetation, grasses cannot grow. Precipitation is partitioned into evaporated from the canopy (after interception) and throughfall (available for surface runoff and infiltration), while the later can be transpired by vegetation depending on stomatal conductance and LAI. Stomatal conductance depends on potential evapotranspiration and soil water potential. Available water depends on the rooting depth, soil depth, and texture prescribed to the model (from FAO 2003 for this study), as does elevation data (Jarvis et al. 2008). 
This equilibrium model does not account for transient changes, as would a dynamic GVM (DGVM); therefore, the modeled future vegetation and hydrology represent the equilibrium that would exist if long-term future climate remained as during the simulated period of 2070 99. The use of an equilibrium GVM is preferred for this study, given the very high spatial resolution and the large number of scenarios. All DGVMs operate under the same water-balance constraint, but are always approaching that constraint (modulating LAI up or down) under a constantly changing climate. The use of a GVM allowed the exploration of a much greater range of uncertainty among climate scenarios with a far greater resolution of the extremely high complexity of Central American terrain.

MAPSS has been satisfactorily calibrated and validated in Mesoamerica with remotely sensed LAI data and runoff in 138 catchments widely distributed across the region of study (Imbach et al. 2010). Validation was based on climate and runoff data for years 1950-2006 and 1950-2008, respectively (see Imbach et al. 2010, their Table 1, for details on datasets used), with parameters of soil depth, stomatal conductance, transpiration, and wilting point calibrated for Mesoamerica. Annual runoff was underestimated by $12 \%$, with relatively better performance in wet areas (with annual precipitation over $2000 \mathrm{~mm}$ ) probably linked to hydrological processes that cannot be captured at monthly time steps over dry areas (i.e., rainstorms) and cloud water interception in cloud forests (Bruijnzeel 2005) not being captured by current precipitation forcings. The bias in simulated annual runoff was tested across gradients of precipitation, altitude, forest cover, and catchment size and showed no trends except for small catchments (less than 10 pixels) probably because of catchment delineation problems. Monthly performance showed that between $78 \%$ and $46 \%$ of catchments performed fairly (or better) depending on the performance coefficient used (Kendall's ranked correlation or Nash-Sutcliffe, respectively). The authors recommended using monthly outputs only for catchments where seasonal water storage in aquifers is not significant because of model limitations to simulate this process (Imbach et al. 2010). The model overestimated LAI in Costa Rica and Panama (southern part of the region) and showed opposite trends in the north. Limitations from remotely sensed data (particularly for this region given its cloud cover) make it difficult to draw conclusions on model performance. However, modeled LAI differences were within the range of differences commonly found in the literature (Imbach et al. 2010). The region is modeled by MAPSS as covered by coexisting trees and grasses under current climate, except for highlands in the northwestern part of Mexico where shrubs replace trees. We chose to only evaluate annual model outputs given the lack of data on groundwater resources and model limitations to simulate aquifer recharge and discharge.

\section{c. Climate scenarios}

We used climate change scenarios produced by the World Climate Research Programme (WCRP) Coupled Model Intercomparison Project phase 3 (CMIP3). The GCM realizations of this multimodel dataset, used in the IPCC Fourth Assessment Report, were downscaled to a 2.5-min resolution (around 5-km pixel) by The Nature Conservancy-California. The climatology dataset has monthly temperature and precipitation averages for the 2070-99 period, including 48, 52, and 36 realizations for low (B1 based on a global sustainable development), intermediate (A1B with a balance between fossil and nonfossil energy sources), and high (A2 based on consolidated regional development) emission scenarios, respectively, from the IPCC Special Report on Emission Scenarios (SRES; Nakicenovic and Swart 2000). The downscaling method consisted of estimating the anomaly as the difference between the future (2070-99) and reference climate (1950-2000) from each GCM realization and interpolating it to a finer resolution $(5 \mathrm{~km})$. The assumption is that the anomaly between the GCM and the observed climatology has a coarse resolution and is linearly stable between the present and the future. As in other similar studies (Hulme et al. 1999; Scholze et al. 2006; VEMAP Members 1995), climate scenarios were constructed by adding the GCM anomaly $(5-\mathrm{km}$ resolution) to our reference climatology (1950-2000) at a 1-km resolution (Hijmans et al. 2005). (A list of the GCM realizations used is provided in the supplemental appendix S1 and Table S1 at http://dx.doi.org/10.1175/ JHM-D-11-023.s1.)

Under all future climate scenarios considered (B1, $\mathrm{A} 1 \mathrm{~B}$, and A2), temperature increases in Mesoamerica at the end of the century range from less than $2.5^{\circ} \mathrm{C}$ (average $\mathrm{B} 1$ scenarios) to more than $3.5^{\circ} \mathrm{C}$ in the northwest part of the region (average A2 scenarios). Precipitation is projected to increase or decrease depending on the location and the scenario (Fig. 2a) with a larger spread of changes with higher emissions (Fig. 2b). On average among the scenarios with decreasing precipitation, the projected change is from $4 \%$ to more than $20 \%$ (larger reductions are observed in dry areas). Uncertainties are the lowest for the highest emission scenarios (A2 group of scenarios). The trend in decreasing precipitation is more certain in the north of the region than in Panama and Costa Rica (Fig. 2a), which stand between areas of decreasing precipitation in the north and areas of increasing precipitation south of the study area, in South America. 


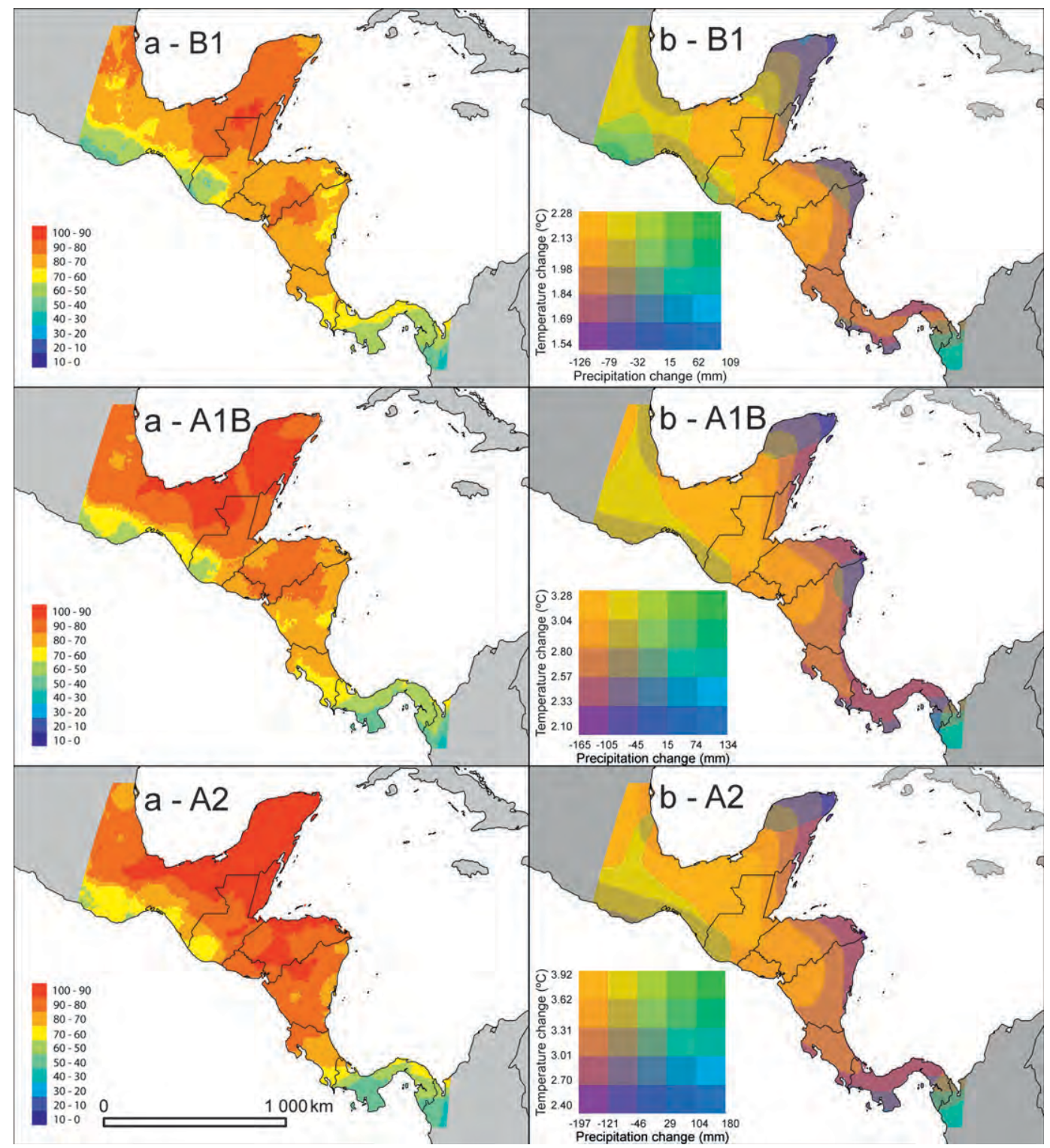

FIG. 2. Precipitation and temperature changes in Mesoamerica under low (B1), moderate (A1B), and high (A2) emission scenarios for 2070-99 (48, 52, and 36 scenarios for B1, A1B, and A2) relative to the 1950-2000 reference period. (a) The likelihood of precipitation change is estimated as the percentage of scenarios showing a decrease in precipitation. (b) Bivariate color maps combine projected precipitation and temperature changes averaged for the ensemble within each emission scenario.

Other studies in tropical areas (Hély et al. 2006) have ignored the effects of elevated atmospheric $\mathrm{CO}_{2}$ concentrations on stomatal conductance, water use efficiency, water balance, and plant growth, because of the lack of knowledge of these processes in tropical areas (Körner 2009) at ecosystem level (Norby and Luo 2004) and of the combined effects of elevated $\mathrm{CO}_{2}$ and temperature change (Hickler et al. 2008). Furthermore, relative to changes in precipitation and temperature, these effects might be relatively small (Chambers and Silver
2004; Körner 2009; Körner and Arnone 1992). However, MAPSS has been run globally with and without a direct $\mathrm{CO}_{2}$ effect, emulated by a $35 \%$ reduction in stomatal conductance under $2 \times \mathrm{CO}_{2}$ scenarios, based on literature available at the time (Neilson and Marks 1994). Elevated $\mathrm{CO}_{2}$ produced larger effects on LAI than on runoff, leaving the potential for large areas of widespread dieback, even under elevated $\mathrm{CO}_{2}$. We tested the effects of increased water use efficiency (WUE) under elevated $\mathrm{CO}_{2}$ concentrations and induced a $20 \%, 37 \%$, and $47 \%$ 
reduction in stomatal conductance for the $\mathrm{B} 1, \mathrm{~A} 1 \mathrm{~B}$, and A2 ensembles.

\section{d. Uncertainty assessment}

We evaluated the uncertainties of the changes in model outputs between the reference period (19502000) and 2070-99 (the period for the future climatology used). For LAI, runoff, and evapotranspiration, we arbitrarily considered changes larger than $20 \%$ in absolute value to be of potentially large significance and lower changes as no-change scenarios (other thresholds were explored; see supplemental Fig. S1 in appendix S2; http://dx.doi.org/10.1175/JHM-D-11-023.s1). For vegetation structure, we considered changes in the dominant canopy vegetation type (e.g., from tree to grass or vice versa). Using the likelihood scale recommended by IPCC (2005) to communicate uncertainty, we considered that a change is "very likely" if it is observed in more than $90 \%$ of the realizations for an ensemble scenario, "likely" if $66 \%-90 \%$, "about as likely as not" from $33 \%$ to $66 \%$, "unlikely" $10 \%-33 \%$, and "very unlikely" less than $10 \%$. We assumed that uncertainty is reduced as the likelihood of change increases and vice versa. We mapped the likelihood of impacts using multicolored maps (Scholze et al. 2006; Teuling et al. 2011). We assumed that all GCMs (and each of their realizations) are independent and of equivalent skill over Mesoamerica, given the lack of references on GCM performance for this region. Accordingly, equal weighting was assigned to all ensemble members.

\section{Results}

\section{a. Runoff and evapotranspiration}

The distribution of changes is highly biased toward runoff reduction (Fig. 3) across the whole region and all scenario ensembles studied. Except for maximum runoff values (across all ensembles and realizations) that showed high runoff increase ( $80 \%$ increase or higher) over large areas in the northern half of the region (Honduras, Belize, Guatemala, and Mexico), most of the region experienced runoff reduction up to the 75th percentile of the ensemble scenarios. The central $\mathrm{Yu}$ catan Peninsula and mountain ranges of Nicaragua, Honduras, and Guatemala showed a consistent runoff reduction of more than $80 \%$ (up to the 75 th percentile of the ensemble scenario). Areas that showed a large increase in runoff (higher than $80 \%$ ) are those with low current runoff (less than $50 \mathrm{~mm} \mathrm{yr}^{-1}$ ) and therefore they remained dry relative to the rest of the study area (i.e., Costa Rica and Panama). (See Fig. 3 for the A2 ensemble and supplemental Fig. S2 in appendix S2 for the B1 and A1B ensembles, respectively; http://dx.doi.org/ 10.1175/JHM-D-11-023.s1.)
Annual runoff is likely to decrease over $61 \%-71 \%$ of the area depending on the ensemble scenario (red areas in Fig. 4a) and likely to increase in less than $1 \%$ (blue areas in Fig. 4a). Uncertainty in predicted changes in runoff is less with higher emissions, as a likely decrease in runoff is observed in larger areas under scenarios A2 than under the other scenarios. Uncertainties about runoff are higher in the northwest of the region, where opposing trends are observed under different realizations (see purple areas in Fig. 4a). In most of the south (Costa Rica and Panama) runoff will likely decrease (Fig. 4a). It is very unlikely that runoff will change in central Honduras and parts of southern Mexico (white areas in Fig. 4a).

The range of changes in evapotranspiration show an increase (of more than $20 \%$ ) on more humid areas (most of Costa Rica and Panama) between the maximum and 25th percentile values of all realizations across ensembles, while realizations with minimum evapotranspiration values showed a range of changes between $-20 \%$ and $20 \%$. The northern part shows milder changes (relative to magnitudes of change in runoff) between $-40 \%$ and $40 \%$. (See Fig. 5 for the A2 ensemble and supplemental Figs. S4 and S5 in appendix S2 for the B1 and $\mathrm{A} 1 \mathrm{~B}$ ensembles, respectively.) Accordingly, we found a likely increase in $18 \%-22 \%$ of the area (blue areas in Fig. 4b), and a likely decrease in less than $1 \%$ of the area. No changes in evapotranspiration are observed in the north (white areas in Fig. 4b). Uncertainty in the likelihood of change in evapotranspiration is higher in the northwest (purple areas in Fig. 4b) than in the rest of the region.

\section{b. Vegetation}

Changes in LAI values show a reduction (of at least $20 \%$ ) except for realizations with maximum LAI values and areas with higher likelihood of shifting to grassdominant vegetation types (elimination of tree cover; see Fig. 4d) where increase in LAI values appear (from the 50th percentile up to maximum value realizations). These areas (showing increase in LAI) are those with the lowest LAI under baseline climate conditions (see Imbach et al. 2010, their Fig 4a). Minimum value realizations across the whole region on all ensemble scenarios show a decrease in LAI values of at least $40 \%$. (See Fig. 7 for the A2 ensemble and Figs. S6 and S7 in appendix S2 for the B1 and A1B ensembles, respectively; http://dx.doi.org/10.1175/JHM-D-11-023.s1.)

LAI is likely to decrease over $77 \%-89 \%$ of the area (red areas in Fig. 4c), depending on the ensemble scenario, and likely to increase over less than $2 \%$ of the area (green areas in Fig. 4c). In areas with less certainty in LAI trends (e.g., in central Panama, Costa Rica, and 


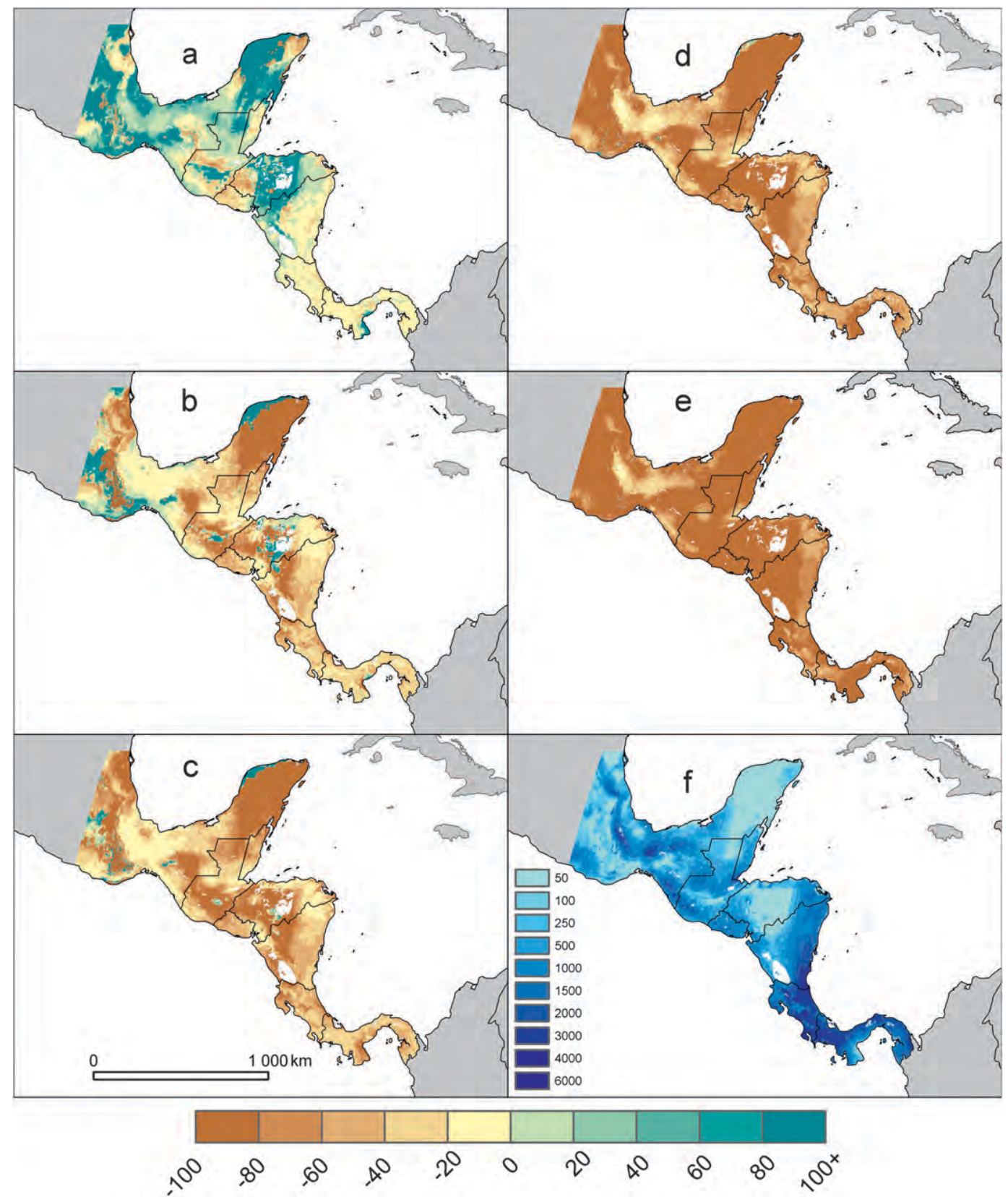

FIG. 3. Change in annual runoff (\%) for the (a) maximum, (b) 75th percentile values, (c) 50th percentile values, (d) 25th percentile values, and (e) minimum of the A2 ensemble scenarios compared to (f) the reference period (1950-2000; mm).

Honduras; coastal Yucatan; and the highlands of El Salvador, Mexico, Guatemala, and Mexico), the scenarios show mixed responses in LAI to these changes in climate (yellow areas in Fig. 4c), as anticipated by Neilson 1993a) for any areas of rapid change (ecotones). The decrease in LAI is generally driven by a decrease in tree and grass LAI (red areas in Figs. 6a,c), except in some areas of Mexico where the change affects shrubdominant vegetation type (Fig. 6b). An increase in grass
LAI (green areas in Fig. 6c) is the driver of the increases in total LAI (green areas in Fig. 6c) in savanna and seasonal ecosystems, indicating an increase in grasses as tree density is reduced.

In some realizations, the woody dominant vegetation type (either trees or shrubs) shifts to grasses (red areas in Fig. 4d) but this trend is uncommon: it is likely in less than $2 \%$ of the area. No changes from grasses to shrubs or trees are expected. 


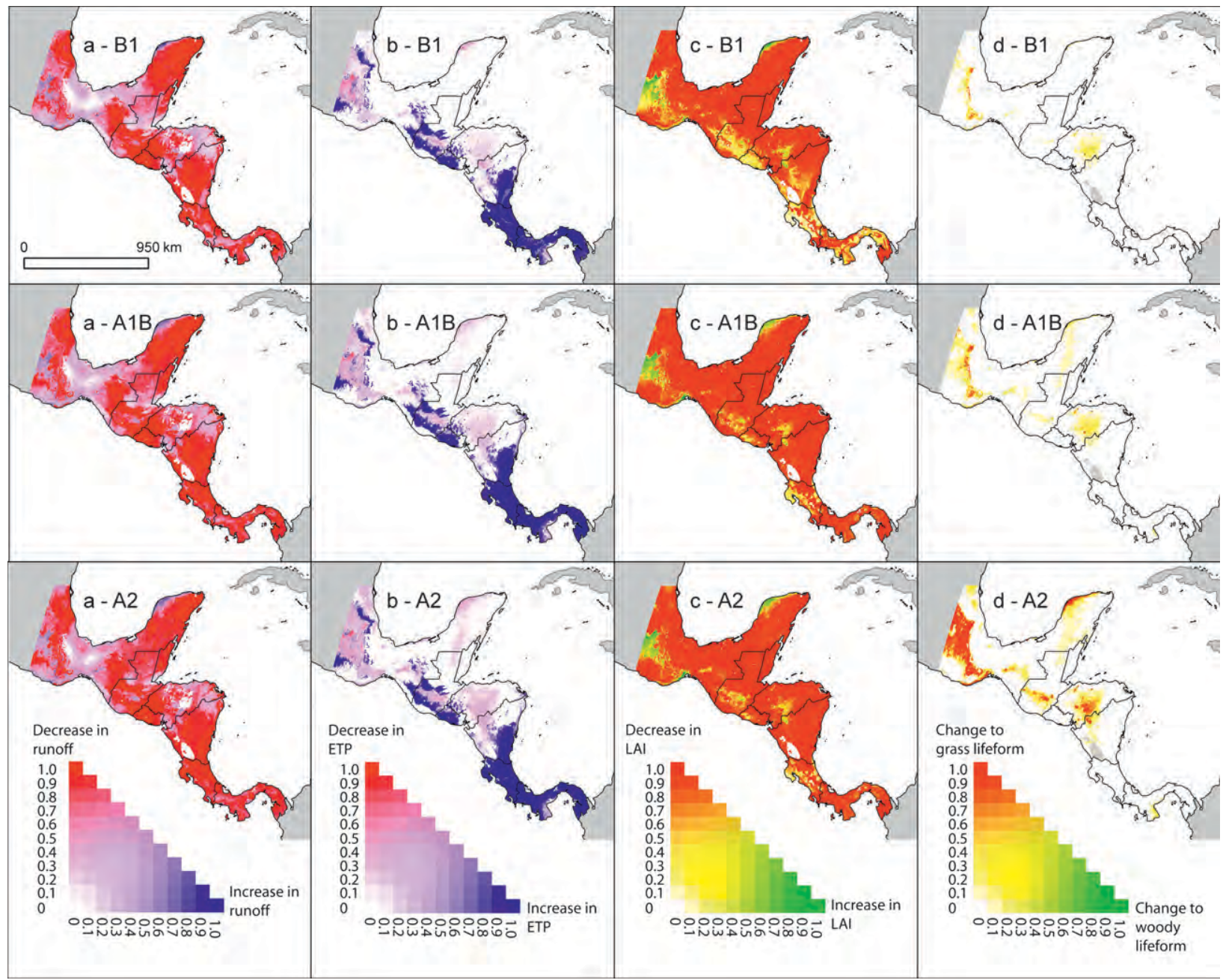

FIG. 4. Fraction of simulations in low (B1), moderate (A1B), and high (A2) emission scenarios showing at least (a) $20 \%$ change in runoff, (b) $20 \%$ in evapotranspiration, (c) $20 \%$ in LAI, or (d) change in dominant vegetation type. The horizontal (vertical) axis of the color map is the fraction of scenarios showing an increase (decrease) in runoff, evapotranspiration, or LAI, or a change from grass to shrub/tree (tree/shrub to grass). Legend values show mean range value for each color class.

\section{c. Simulating $\mathrm{CO}_{2}$ effect on WUE}

Simulations accounting for the effect of increased $\mathrm{CO}_{2}$ concentrations on WUE show similar patterns of likelihood of changes on runoff (Fig. 8a for B1 and A2 scenarios) and evapotranspiration (supplemental Fig. S8 in appendix S2). Annual runoff is likely to decrease (at least $20 \%$ ) over $56 \%-61 \%$ of the area, depending on the ensemble scenario (red areas in Fig. 8a), and likely to increase in less than 2\% (blue areas in Fig. 8a). Evapotranspiration is likely to increase in $14 \%-17 \%$ of the area and likely to decrease in less than $3 \%$ of the area (see supplemental Fig. S8 in appendix S2; http://dx.doi. org/10.1175/JHM-D-11-023.s1). Changes in dominant vegetation types have similar patterns to simulations without $\mathrm{CO}_{2}$ effects with likely changes in $<1 \%$ of the study area. The main difference on simulated $\mathrm{CO}_{2}$ effects (compared to simulations without increased WUE) was a likely decrease in LAI for $7 \%-16 \%$ of the area (compared to over $77 \%$ in previous simulations) and a likely increase in LAI in 7\% of the area for the A2 ensemble (compared to less than $1 \%$ in previous simulations) (Fig. 8b for B1 and A2 scenarios and supplemental Fig. S8 of appendix S2).

\section{Summary and discussion}

Climatic changes in the water cycle reflect changes in precipitation, temperature, and humidity that can produce major changes in vegetation density and structure. These vegetation changes produce strong, nonlinear changes in all hydrological processes-most notably runoff. However, the vegetation gets access to the infiltrated precipitation before it reaches the streamflow. 


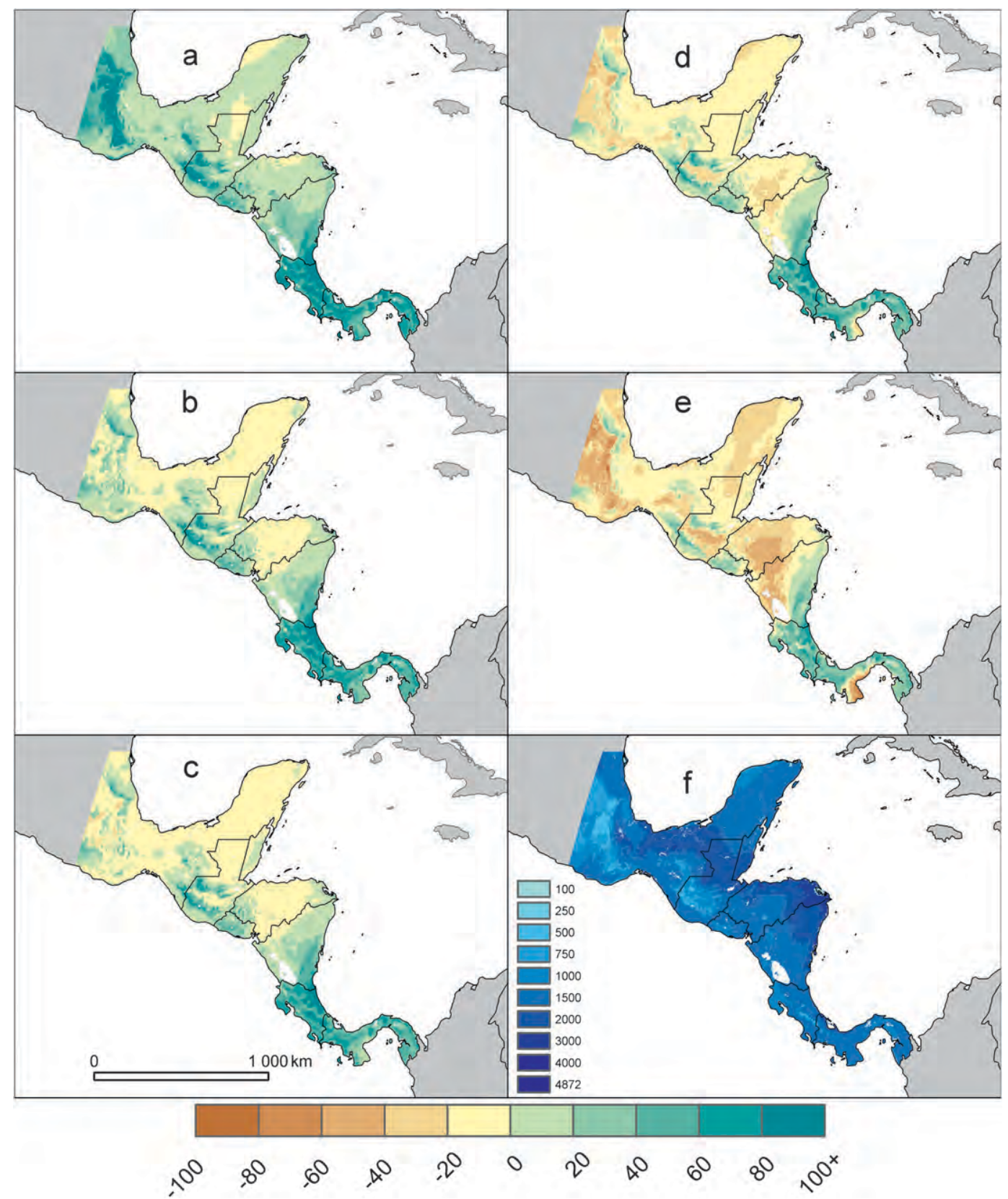

FIG. 5. Same as Fig. 3 except for change in annual evapotranspiration.

Since the tendency of vegetation is to either grow more leaves or lose leaves, depending on available soil water, it acts as a buffering system with respect to runoff. Vegetation will lose leaves (or die off) when soils are dry, transpiring less, and thus leaving more water for runoff. Likewise if there is more soil water, more leaves will grow, transpiring more, and thus reducing runoff. The net effect is to act as a buffer on streamflow to the extent it can within the constraints of the climate. In cases where the water balance becomes too constrained to support a forest, the vegetation will shift to a savanna, shrubland, or grassland. Even though there may be more LAI, grasses cannot access deep soil moisture and its lower profile reduces the turbulent transfer, reducing transpiration and maintaining streamflow.

Traditional hydrologic assessments, using state-of-theart runoff models, such as the Variable Infiltration Capacity model (VIC), use a fixed vegetation structure and annually invariant monthly LAI (Liang et al. 1994; Nijssen et al. 2001). Although these are excellent models under 


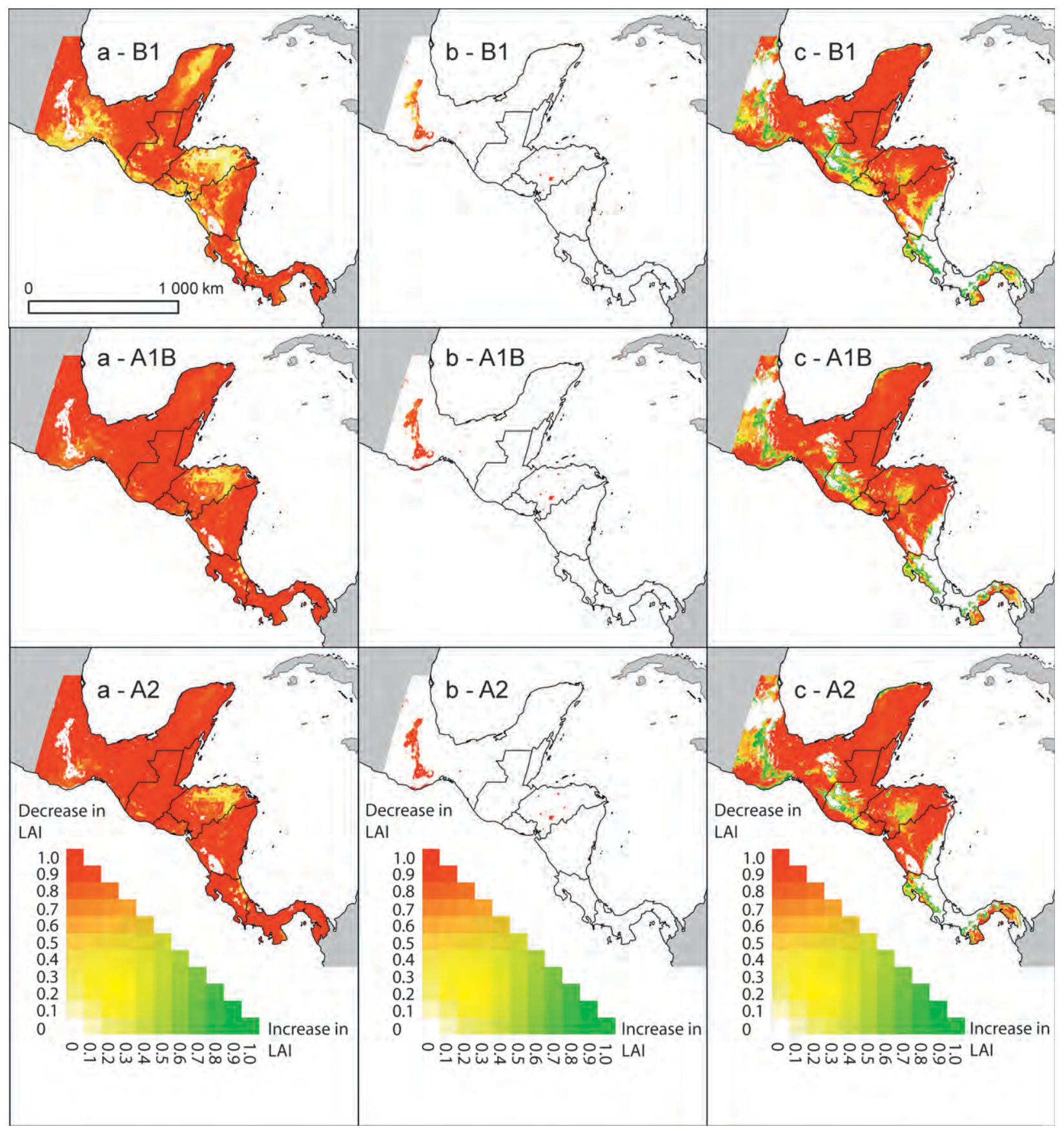

FIG. 6. Same as Fig. 4 except for showing a change of at least $20 \%$ change in LAI of (a) trees, (b) shrubs, and (c) grasses. The horizontal (vertical) axis of the color map is the fraction of scenarios showing an increase (decrease).

present climate conditions, they cannot reflect the myriad of complex nonlinear interactions in the water cycle that are due to the presence of dynamic vegetation under a changing climate. The climate change signal that is "absorbed" by the vegetation would impact the streamflow. For example, if the soils become drier, dynamic vegetation would reduce LAI, maintaining water in the stream, whereas static vegetation would attempt to draw more water and either show an artificial drought stress or significantly reduced streamflow, possibly of opposite sign change to that produced with dynamic vegetation.

Under a general drying trend in climate scenarios (lower precipitation and higher temperatures), we found that runoff, evapotranspiration, and LAI have mixed (positive and negative) spatial patterns of change. These changes result from nonlinear interactions between climate and 


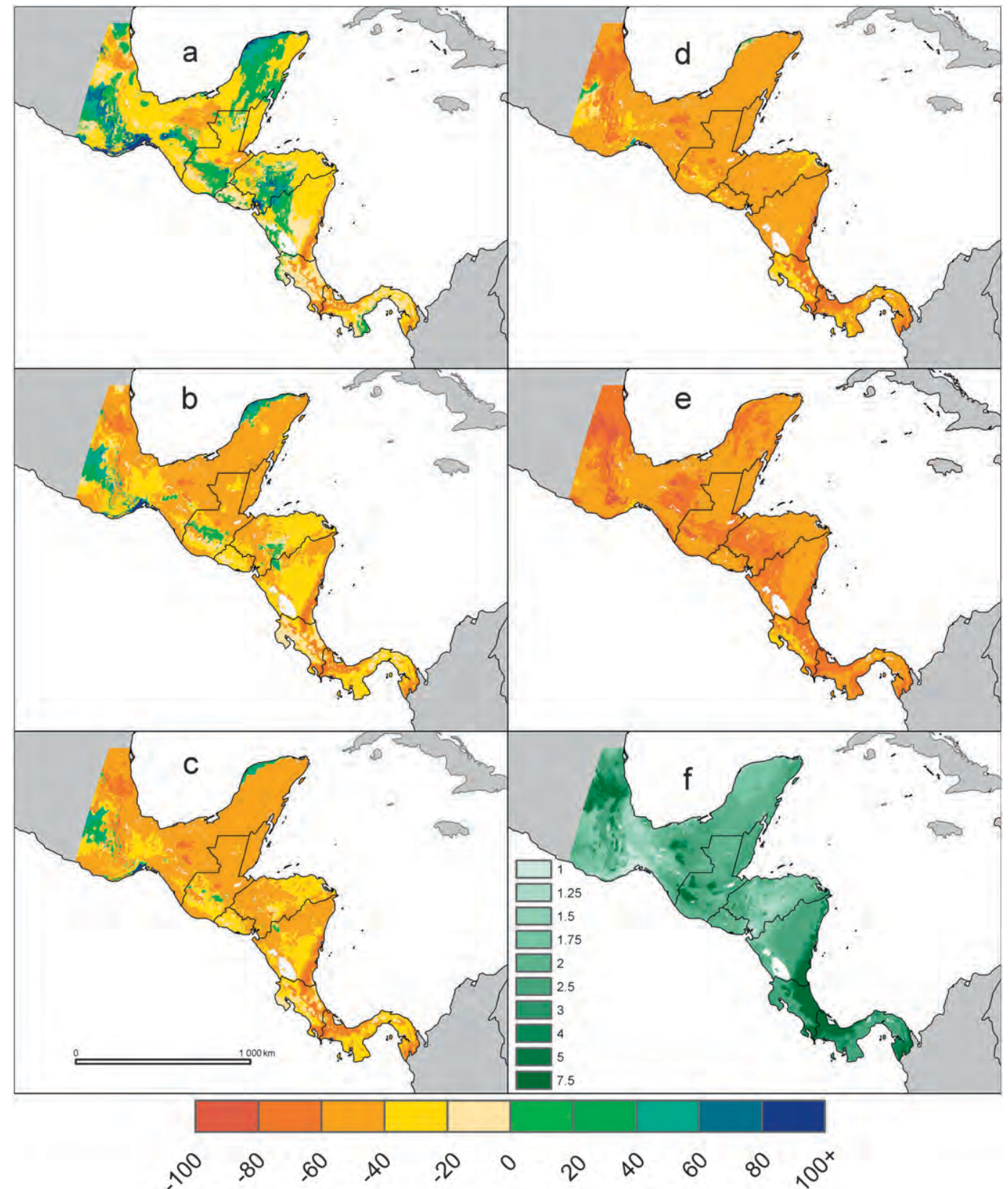

FIG. 7. Same as Fig. 3 except for change in LAI (\%).

vegetation that buffer the impact on the water balance. The complexity of changes is exemplified in the following paragraphs that describe three nonintuitive cases under the A2 scenario, two over the Yucatán Peninsula, and one on the border between Nicaragua and Honduras:

1) In the northwestern part of the Peninsula, there were large runoff increases (more than $80 \%$; Figs. $3 \mathrm{~b}-\mathrm{d}$ ) along with mild evapotranspiration reductions $(0 \%-20 \%$; Figs. $5 b-d)$, but seemingly anomalous
LAI increases $(0 \%-60 \%$; Figs. $7 b-d)$. These nonintuitive changes arise from the elimination of tree cover (Fig. 4d-A2) and its replacement by grasses with lower canopy turbulent transfer and less evaporative demand, even with higher total LAI than that of the former forest. Thus, there is a runoff increase under more water-stressed climate conditions.

2) In contrast, the central part of the peninsula showed high runoff reductions (more than $80 \%$; Figs. $3 \mathrm{~b}-\mathrm{d}$ ) along with mild evapotranspiration reductions (up 


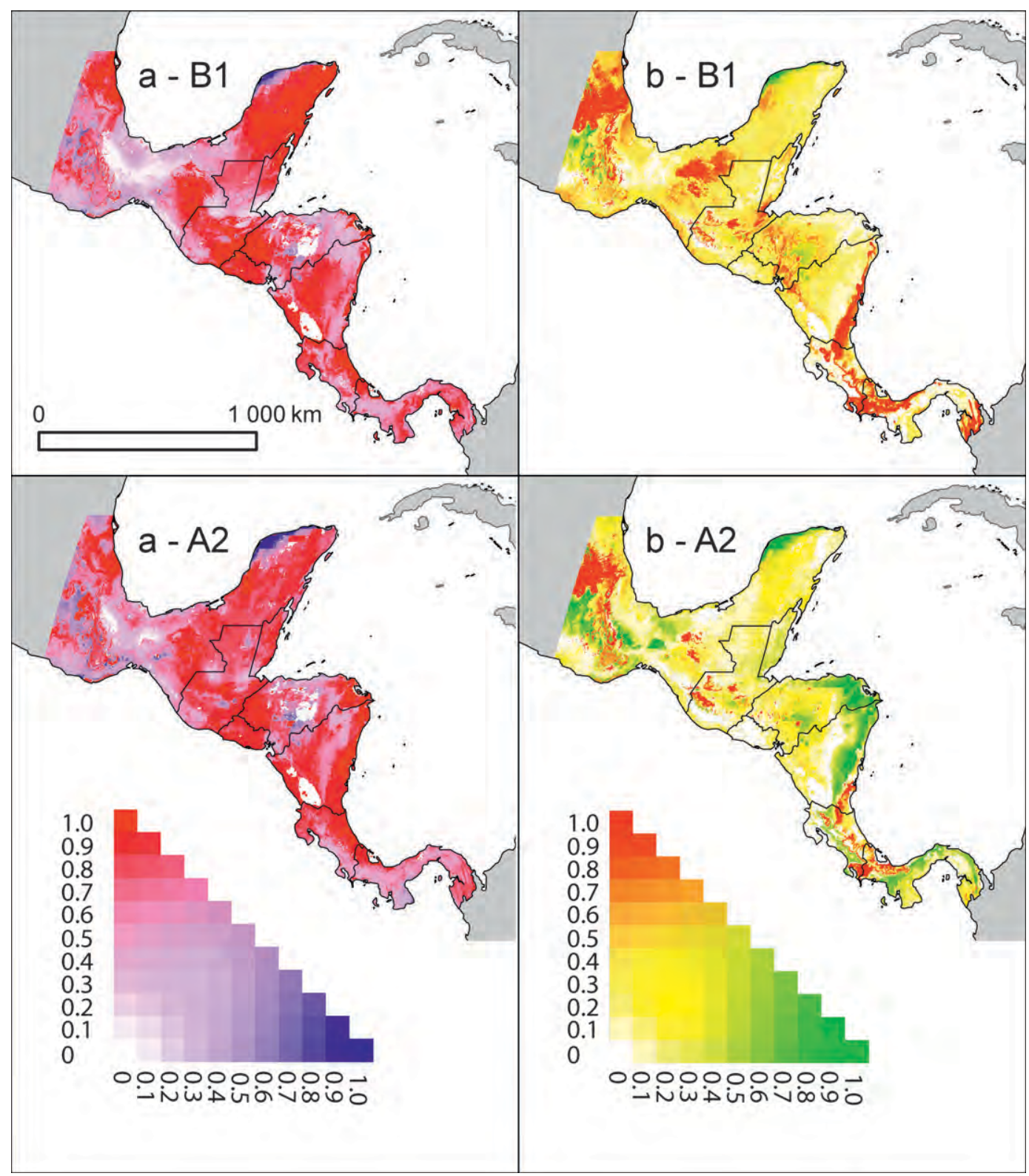

FIG. 8. Same as Fig. 4 except for showing at least $20 \%$ change in (a) runoff and (b) LAI observed in simulations accounting for $\mathrm{CO}_{2}$ effect on water use efficiency. The horizontal (vertical) axis of the color map is the fraction of scenarios showing an increase (decrease) in runoff or LAI.

to $20 \%$; Figs. $5 \mathrm{~b}-\mathrm{d})$ apparently consistent with LAI decreases (between $40 \%$ and $60 \%$; Figs. $7 \mathrm{~b}-\mathrm{d}$ ). In this case, more stressful conditions (increased temperature and decreased precipitation) reduced but did not eliminate the tree cover, as in the previous example. The trees, with a high turbulent transfer and evaporative demand, transpired most of the water leaving much less for runoff.

In these two cases we have drier conditions yet show two different responses in the water balance, but with significantly different changes in system structure. In the first, more stressful case, there was a large shift in the state of the system as trees were lost and runoff increased. In the second, less stressful case, the milder change in vegetation retained a reduced tree cover and showed runoff decreases as most of the water was consumed by vegetation.

3) A third example from the eastern border between Honduras and Nicaragua further highlights these nonintuitive, nonlinear interactions. It shows a milder runoff reduction $(0 \%-40 \%$; Figs. $3 \mathrm{~b}-\mathrm{d})$ along with 
mild changes in evapotranspiration $( \pm 20 \%$; Figs. 5 bd), but with significant LAI reductions (between 20\% and $40 \%$; Figs. $7 \mathrm{~b}-\mathrm{d}$ ). With increased evaporative demand, vegetation density is reduced while evapotranspiration is maintained, resulting in a reduction in runoff, albeit not as great as in the central part of the Yucatan Peninsula (second case shown above).

In some areas runoff is likely to decrease even though precipitation change is uncertain. We found likely runoff decreases and evapotranspiration increases in most of Panama and southern Costa Rica where $30 \%-60 \%$ of the realizations show an increase in precipitation. The increased certainty of the impacts is due to the increase in temperature (across all scenarios) that drives a nonlinear increase in evapotranspiration, reducing runoff. Accordingly, higher emissions produced lower uncertainty (higher likelihood of changes for an ensemble of scenarios) on ecosystems and hydrologic responses.

Runoff is likely to increase in areas where grass LAI increases and where evapotranspiration decreases - mostly central Honduras, Guatemala, and mountains in Mexico. Grass LAI increases because of a reduction in tree LAI (opening of the tree canopy increases light for grass growth), leading to a decrease in evapotranspiration compared to current climate conditions (see examples above). This trend is observed in relatively dry areas, where current annual runoff and precipitation are less than 200 and $1000 \mathrm{~mm}$, respectively, and results from the reduction in deep woody roots, which extract deep water. Summarizing, water-controlled ecosystems showed a reduction in evapotranspiration.

The increase in evapotranspiration in humid areas is driven by the increase in temperatures, which offsets the effect of decreased LAI, which is to reduce evapotranspiration. Therefore, in these areas, the virtually likely increase in temperature results in a likely decrease in runoff, even where the future trend in precipitation is uncertain. In drier areas, runoff can increase even though the future climate appears to be drier because decreased water availability reduces vegetation LAI, evapotranspiration, and woody roots and causes a larger fraction of precipitation to run off (Aber et al. 2001).

Future changes in LAI and potential vegetation types imply modifications in the density and structure of vegetation, ecosystems, and their functions, particularly in areas where a shift from tree- to grass-dominated vegetation types is expected. Mesoamerican ecosystems will shift to drier types, particularly in areas where runoff and evapotranspiration are both reduced indicating that precipitation falls below the potential evapotranspiration, and the water availability for vegetation is reduced (i.e., central Yucatan). Increased evapotranspiration in other areas (e.g., Costa Rica and Panama) indicate that under climate change the runoff-to-evapotranspiration ratio decreases and a larger fraction of precipitation can still be used by vegetation. In general, the use of coupled vegetation and hydrologic responses tends to buffer the magnitude of variability of impacts (i.e., on runoff) that would occur in a typical hydrologic model with a fixed LAI.

Simulations accounting for increased water use efficiency due to higher $\mathrm{CO}_{2}$ concentrations showed that the impacts on runoff remained almost the same (generalized high reductions) while the impacts on vegetation were highly reduced (compared to simulations without the $\mathrm{CO}_{2}$ effect) and new areas show increased LAI, mostly over the Atlantic coastal areas of Nicaragua and Honduras. This highlights the potential importance of this effect on mitigating the impact of precipitation and temperature change on vegetation, while impacts on runoff seem unavoidable and with fixed patterns across the region.

A global study by Scholze et al. (2006), using the Lund-Potsdam-Jena (LPJ) dynamic vegetation model at a coarser resolution, found qualitatively similar trends for runoff and LAI changes in Mesoamerica but with differences compared to our study; for example, larger areas of forest loss and increased runoff in the southern part of the region as opposed to the likely decreased runoff found in our study. Comparing the two studies is not straightforward because of the vastly different spatial resolutions (approximately 180- versus $1-\mathrm{km}$ pixel) and the differently grouped climate realizations (by range of temperature increase versus by emission scenarios in our study). Also, the different results may come from the different thresholds used to estimate changes (33\% of observed variability versus $20 \%$ in our study). These different resolutions and thresholds may explain the smaller likelihood values in our study. Yet, it is encouraging (regarding uncertainties) to see similarities in the vegetation shifts between the results of the high-resolution climate scenarios used in MAPSS and those of the more coarseresolution scenarios in the LPJ.

Finally, the interactions between gradual climate change and other drivers of changes in ecosystems and the water cycle (not accounted for in this study) can be also important: (i) feedbacks between vegetation change and fires, as changes in fire regimes may affect ecosystems and the climate-induced conversion of forests to grasslands can modify fire regimes (Lewis 2006) (MAPSS contains a simplified fire algorithm); (ii) hurricane and extreme events, which can be modified by climate change and have impacts on the structure of forests (i.e., stem density and tree height) (Gillespie et al. 2006) and on the water balance, depending on the 
ecosystem type (Knapp et al. 2008); (iii) intra- and interannual climate variability, as variability affects the distribution of vegetation types in Mesoamerica (LozanoGarcía et al. 2007), which is especially enhanced in complex topography (Neilson 1993a); and (iv) human disturbances, such as deforestation, degradation, and fragmentation, influence water cycles (Piao et al. 2007).

\section{Future work}

Using the MAPSS model and 136 GCM realizations, we evaluated the likelihood and magnitude of the impacts of climate change on potential vegetation and the water cycle in Mesoamerica. Even though the trend in future precipitation in the region is highly uncertain, the impacts of climate change on vegetation and water cycle are predicted with relatively low uncertainty. Projected climate change will likely reduce runoff and LAI of vegetation across most of the region. Impacts on LAI will largely depend on whether water use efficiency is increased under higher $\mathrm{CO}_{2}$ concentrations at ecosystem level. Results call for an urgent consideration of climate change issues in biodiversity and water management policies.

The MAPSS-modeled changes in tree fractional cover, which result in structural ecosystem changes, call for in-depth future studies of plant populations, species, and community ecology. For example, changes in the dominant form (from trees to grasses) imply changes in seed sizes (Moles et al. 2007) and a modification of migration rate - a capacity that is important for forming new species assemblages depending on where future new climates as well as current analogs will be located in Mesoamerica (Neilson et al. 2005; Williams et al. 2007). Changes in vegetation will also affect forest carbon stocks (Bunker et al. 2005). Since LAI can be used as a proxy for the storage of carbon in soils and vegetation (Bachelet et al. 2001; Neilson 1993b), we can infer that Mesoamerican ecosystems may be atmospheric carbon sources under future climate. Studies with dynamic vegetation models at coarse spatial resolutions suggest that this trend will be apparent in the second half of the century (Cramer et al. 2001).

Changes in vegetation have implications for biodiversity. Our results highlight the potential vulnerability of ecosystems in relatively drier areas (i.e., northern part of the region) and their importance as a source of genes and species that could help ecosystems shifting to drier types-for example, the Mexican dry forests (Dick and Wright 2005). This could mean that changes in the network of protected areas and biological corridors of the Mesoamerican Biological Corridor (MBC) are needed, as it has been suggested for Canada's national park system (Scott et al. 2002). However, in terrain as complex as this, even a 1-km grid cell resolution is coarse and microsites much smaller than that will abound. Thus, the likelihood of refugia in terrain such as this is considerably high and could moderate our conclusions a bit.

Changes in the water cycle will also have implications for terrestrial biodiversity. Water availability has been used as a determinant of plant species richness in warm areas (Hawkins et al. 2003) because climate and ecosystem productivity influence species richness (Field et al. 2009; Kreft and Jetz 2007). For example, evapotranspiration was found to be correlated with global richness of vascular plants (Kreft and Jetz 2007) as well as terrestrial vertebrates of the Neotropics (Qian 2010).

Finally, this regional assessment could provide general trends on the impacts of future availability of surface water (for drinking water, irrigation, or hydroenergy) and biomass (for household firewood energy or forestry sectors) at scales below regional level.

Acknowledgments. This work was funded by the MESOTERRA Project of the Mesoamerican AgroEnvironmental Program at the Tropical Agricultural Research and Higher Education Center (CATIE) and the Climate Change and Biodiversity Effects (CLIMBE) project financed by the BBVA Foundation. We acknowledge the Program for Climate Model Diagnosis and Intercomparison (PCDMI) and the WCRP's Working Group on Coupled Modelling (WGCM) for their roles in making available the WCRP CMIP3 multimodel dataset. The creation of this dataset was supported by the Office of Science, U.S. Department of Energy. We thank The Nature Conservancy-California and Kirk Klausmeyer for downscaling and converting the climate data to ArcGIS format. We thank the anonymous reviewers for their role in considerably improving this manuscript.

\section{REFERENCES}

Aber, J., R. P. Neilson, S. McNulty, J. M. Lenihan, D. Bachelet, and R. J. Drapek, 2001: Forest processes and global environmental change: Predicting the effects of individual and multiple stressors. Bioscience, 51, 735-751.

Aguilar, E., and Coauthors, 2005: Changes in precipitation and temperature extremes in Central America and northern South America, 1961-2003. J. Geophys. Res., 110, D23107, doi:10. 1029/2005JD006119.

Bachelet, D., M. Brugnach, and R. P. Neilson, 1998: Sensitivity of a biogeography model to soil properties. Ecol. Modell., 109, 77-98.

_ R. R. Neilson, J. M. Lenihan, and R. J. Drapek, 2001: Climate change effects on vegetation distribution and carbon budget in the United States. Ecosystems, 4, 164-185.

Bishop, G. D., M. R. Church, J. D. Aber, R. P. Neilson, S. V. Ollinger, and C. Daly, 1998: A comparison of mapped estimates of longterm runoff in the northeast United States. J. Hydrol., 206, 176-190. 
Bruijnzeel, L., 2005: Tropical montane cloud forests: A unique hydrological case. Forests, Water and People in the Humid Tropics: Past, Present and Future Hydrological Research for Integrated Land and Water Management, M. Bonell and L. Bruijnzeel, Eds., Cambridge University Press, 462-484.

Bunker, D. E., F. DeClerck, J. C. Bradford, R. K. Colwell, I. Perfecto, O. L. Phillips, M. Sankaran, and S. Naeem, 2005: Species loss and aboveground carbon storage in a tropical forest. Science, 310, 1029-1031.

Chambers, J., and W. Silver, 2004: Some aspects of ecophysiological and biogeochemical responses of tropical forests to atmospheric change. Philos. Trans. Roy. Soc. London, B359, 463-476.

Conservation International, cited 2011: Mesoamerica. [Available online at http://www.conservation.org/where/priority areas/hotspots/north_central_america/Mesoamerica/Pages/ biodiversity.aspx.]

Cramer, W., and Coauthors, 2001: Global response of terrestrial ecosystem structure and function to $\mathrm{CO}_{2}$ and climate change: Results from six dynamic global vegetation models. Global Change Biol., 7, 357-373.

Curtis, J. H., D. A. Hodell, and M. Brenner, 1996: Climate variability on the Yucatan Peninsula (Mexico) during the past 3500 years, and implications for Maya cultural evolution. Quat. Res., 46, 37-47.

Dai, A., 2010: Drought under global warming: A review. Wiley Interdiscip. Rev.: Climate Change, 2, 45-65.

DeClerck, F. A. J., and Coauthors, 2010: Biodiversity conservation in human-modified landscapes of Mesoamerica: Past, present and future. Biol. Conserv., 143, 2301-2313.

Dick, C. W., and S. J. Wright, 2005: Tropical mountain cradles of dry forest diversity. Proc. Natl. Acad. Sci. USA, 102, $10757-$ 10758.

FAO, 2003: Digital Soil Map of the World and Derived Soil Properties. Land and Water Digital Media Series 1, Food and Agriculture Organization of the United Nations, CD-ROM.

Field, R., and Coauthors, 2009: Spatial species-richness gradients across scales: A meta-analysis. J. Biogeogr., 36, 132-147.

Gentry, A. H., 1982: Neotropical floristic diversity: Phytogeographical connections between Central and South America, Pleistocene climatic fluctuations, or an accident of the Andean orogeny? Ann. Mo. Bot. Gard., 69, 557-593.

Gillespie, T. W., B. R. Zutta, M. K. Early, and S. Saatchi, 2006: Predicting and quantifying the structure of tropical dry forests in south Florida and the Neotropics using spaceborne imagery. Global Ecol. Biogeogr., 15, 225-236.

Giorgi, F., 2006: Climate change hot-spots. Geophys. Res. Lett., 33, L08707, doi:10.1029/2006GL025734.

Greenheck, F. M., 2002: Naturaleza, gente y bienestar: Mesoamérica en cifras. Comisión Centroamericana de Ambiente y Desarrollo (CCAD) y Sistema de la Integración Centroamericana (SICA), $39 \mathrm{pp}$.

Haug, G. H., D. Günther, L. C. Peterson, D. M. Sigman, K. A. Hughen, and B. Aeschlimann, 2003: Climate and the collapse of Maya civilization. Science, 299, 1731-1735.

Hawkins, B. A., and Coauthors, 2003: Energy, water, and broadscale geographic patterns of species richness. Ecology, 84, 3105-3117.

Hély, C., L. Bremond, S. Alleaume, B. Smith, M. T. Sykes, and J. Guiot, 2006: Sensitivity of African biomes to changes in the precipitation regime. Global Ecol. Biogeogr., 15, 258-270.

Hickler, T., B. Smith, I. C. Prentice, K. Mjöfors, P. Miller, A. Arneth, and M. T. Sykes, 2008: $\mathrm{CO}_{2}$ fertilization in temperate FACE experiments not representative of boreal and tropical forests. Global Change Biol., 14, 1531-1542.

Hijmans, R. J., S. E. Cameron, J. L. Parra, P. G. Jones, and A. Jarvis, 2005: Very high resolution interpolated climate surfaces for global land areas. Int. J. Climatol., 25, 1965-1978.

Horton, R. E., 1933: The role of infiltration in the hydrologic cycle. Eos, Trans. Amer. Geophys. Union, 14, 446-460.

Hulme, M., E. M. Barrow, N. W. Arnell, P. A. Harrison, T. C. Johns, and T. E. Downing, 1999: Relative impacts of humaninduced climate change and natural climate variability. $\mathrm{Na}$ ture, 397, 688-691.

Imbach, P., L. Molina, B. Locatelli, O. Roupsard, P. Ciais, L. Corrales, and G. Mahé, 2010: Climatology-based regional modelling of potential vegetation and average annual long-term runoff for Mesoamerica. Hydrol. Earth Syst. Sci., 14, 1801-1817.

IPCC, 2005: Guidance notes for lead authors of the IPCC Fourth Assessment Report on addressing uncertainties. Intergovernmental Panel on Climate Change, 4 pp.

Jarvis, A., H. Reuter, A. Nelson, and E. Guevara, cited 2008: Holefilled seamless SRTM data V4. International Center for Tropical Agriculture (CIAT). [Available online at http://srtm.csi.cgiar. org.]

Knapp, A. K., and Coauthors, 2008: Consequences of more extreme precipitation regimes for terrestrial ecosystems. Bioscience, 58, 811-821.

Körner, C., 2009: Responses of humid tropical trees to rising $\mathrm{CO}_{2}$. Annu. Rev. Ecol. Evol. Syst., 40, 61-79.

, and J. A. Arnone III, 1992: Responses to elevated carbon dioxide in artificial tropical ecosystems. Science, 257, 16721675.

Kreft, H., and W. Jetz, 2007: Global patterns and determinants of vascular plant diversity. Proc. Natl. Acad. Sci. USA, 104, 59255930.

Lewis, S. L., 2006: Tropical forests and the changing earth system. Philos. Trans. Roy. Soc. London, B361, 195-210.

Liang, X., D. P. Lettenmaier, E. F. Wood, and S. J. Burges, 1994: A simple hydrologically based model of land surface water and energy fluxes for general circulation models. J. Geophys. Res., 99, 14 415-14 428.

Lozano-García, M. S., M. Caballero, B. Ortega, A. Rodríguez, and S. Sosa, 2007: Tracing the effects of the Little Ice Age in the tropical lowlands of eastern Mesoamerica. Proc. Natl. Acad. Sci. USA, 104, 16 200-16 203.

MacFadden, B. J., 2006: Extinct mammalian biodiversity of the ancient New World tropics. Trends Ecol. Evol., 21, 157165.

Magaña, V., J. A. Amador, and S. Medina, 1999: The midsummer drought over Mexico and Central America. J. Climate, 12, $1577-1588$

Malhi, Y., and J. Wright, 2004: Spatial patterns and recent trends in the climate of tropical rainforest regions. Philos. Trans. Roy. Soc. London, B359, 311-329.

MEA, Ed., 2005: Ecosystems and Human Well-Being: Synthesis Report. Millennium Ecosystem Assessment Series, 137 pp. [Available online at http://www.maweb.org/documents/document. 356.aspx.pdf.]

Moles, A. T., and Coauthors, 2007: Global patterns in seed size. Global Ecol. Biogeogr., 16, 109-116.

Myers, N., R. A. Mittermeier, C. G. Mittermeier, G. A. B. da Fonseca, and J. Kent, 2000: Biodiversity hotspots for conservation priorities. Nature, 403, 853-858.

Nakicenovic, N., and R. Swart, Eds., 2000: Special Report on Emissions Scenarios. Cambridge University Press, 599 pp. 
Neelin, J. D., M. Münnich, H. Su, J. E. Meyerson, and C. E. Holloway, 2006: Tropical drying trends in global warming models and observations. Proc. Natl. Acad. Sci. USA, 103, 6110-6115.

Neilson, R. P., 1993a: Transient ecotone response to climatic change: Some conceptual and modelling approaches. Ecol. Appl., 3, 385-395.

, 1993b: Vegetation redistribution: A possible biosphere source of $\mathrm{CO}_{2}$ during climatic change. Water Air Soil Pollut., 70, 659-673.

, 1995: A model for predicting continental-scale vegetation distribution and water balance. Ecol. Appl., 5, 362-385.

— tation and hydrologic sensitivities from climatic change. J. Veg. Sci., 5, 715-730.

—_, and R. J. Drapek, 1998: Potentially complex biosphere responses to transient global warming. Global Change Biol., 4, 505-521.

— L. F. Pitelka, A. M. Solomon, R. Nathan, G. F. Midgley, J. M. Fragoso, H. Lischke, and K. Thompson, 2005: Forecasting regional to global plant migration in response to climate change. Bioscience, 55, 749-759.

Nijssen, B., G. M. O'Donnell, D. P. Lettenmaier, D. Lohmann, and E. F. Wood, 2001: Predicting the discharge of global rivers. J. Climate, 14, 3307-3323.

Norby, R. J., and Y. Luo, 2004: Evaluating ecosystem responses to rising atmospheric $\mathrm{CO}_{2}$ and global warming in a multi-factor world. New Phytol., 162, 281-293.

Piao, S., P. Friedlingstein, P. Ciais, N. de Noblet-Ducoudré, D. Labat, and S. Zaehle, 2007: Changes in climate and land use have a larger direct impact than rising $\mathrm{CO}_{2}$ on global river runoff trends. Proc. Natl. Acad. Sci. USA, 104, 15242 15247.

Qian, H., 2010: Environment-richness relationships for mammals, birds, reptiles, and amphibians at global and regional scales. Ecol. Res., 25, 629-637.
Scholze, M., W. Knorr, N. W. Arnell, and I. C. Prentice, 2006: A climate-change risk analysis for world ecosystems. Proc. Natl. Acad. Sci. USA, 103, 13 116-13 120.

Scott, D., J. R. Malcolm, and C. Lemieux, 2002: Climate change and modelled biome representation in Canada's national park system: Implications for system planning and park mandates. Global Ecol. Biogeogr., 11, 475-484.

Sechrest, W., T. M. Brooks, G. A. B. da Fonseca, W. R. Konstant, R. A. Mittermeier, A. Purvis, A. B. Rylands, and J. L. Gittleman, 2002: Hotspots and the conservation of evolutionary history. Proc. Natl. Acad. Sci. USA, 99, 2067-2071.

Solomon, S., D. Qin, M. Manning, M. Marquis, K. Averyt, M. M. B Tignor, H. L. Miller Jr., and Z. Chen, Eds., 2007: Climate Change 2007: The Physical Science Basis. Cambridge University Press, 996 pp.

Teuling, A. J., R. Stöckli, and S. I. Seneviratne, 2011: Bivariate colour maps for visualizing climate data. Int. J. Climatol., 31, 1408-1412.

VEMAP Members, 1995: Vegetation/Ecosystem Modeling and Analysis Project: Comparing biogeography and biogeochemistry models in a continental-scale study of terrestrial ecosystem responses to climate change and $\mathrm{CO}_{2}$ doubling. Global Biogeochem. Cycles, 9, 407-437.

Vreugdenhil, D., J. Meerman, A. Meyrat, L. Diego Gómez, and D. J. Graham, 2002: Map of the ecosystems of Central America. World Bank Final Rep., 56 pp.

Weir, J. T., E. Bermingham, and D. Schluter, 2009: The Great American Biotic Interchange in birds. Proc. Natl. Acad. Sci. USA, 106, 21 737-21 742.

Williams, J. W., S. T. Jackson, and J. E. Kutzbach, 2007: Projected distributions of novel and disappearing climates by $2100 \mathrm{AD}$. Proc. Natl. Acad. Sci. USA, 104, 5738-5742.

Yates, D. N., T. G. F. Kittel, and R. F. Cannon, 2000: Comparing the correlative Holdridge model to mechanistic biogeographical models for assessing vegetation distribution response to climatic change. Climatic Change, 44, 59-87. 


\section{(C) Copyright 2012 American Meteorological Society (AMS).}

Permission to use figures, tables, and brief excerpts from this work in scientific and educational works is hereby granted provided that the source is acknowledged. Any use of material in this work that is determined to be "fair use" under Section 107 of the U.S. Copyright Act or that satisfies the conditions specified in Section 108 of the U.S. Copyright Act (17 USC §108, as revised by P.L. 94-553) does not require the AMS's permission. Republication, systematic reproduction, posting in electronic form, such as on a web site or in a searchable database, or other uses of this material, except as exempted by the above statement, requires written permission or a license from the AMS. Additional details are provided in the AMS Copyright Policy, available on the AMS Web site located at (http://www.ametsoc.org/) or from the AMS at 617-227-2425 or copyright@ametsoc.org.

\section{American Meteorological Society Copyright Policy}

(Accepted by the AMS Council 22 September 2010)

\section{http://www.ametsoc.org/pubs/copyrightinfo/ams copyright policy 2010.pdf}

\section{Open access institutional repositories:}

The AMS understands there is increasing demand for institutions to provide open access to the published research being produced by employees, such as faculty, of that institution. In recognition of this, the AMS grants permission to each of its authors to deposit the definitive version of that author's published AMS journal article in the repository of the author's institution provided all of the following conditions are met:

- The article lists the institution hosting the repository as the author's affiliation.

- The copy provided to the repository is the final published PDF of the article (not the EOR version made available by AMS prior to formal publication; see section 6).

- The repository does not provide access to the article until six months after the date of publication of the definitive version by the AMS.

- The repository copy includes the AMS copyright notice. 